\title{
EVALUASI DAMPAK MORATORIUM PERIZINAN KAPAL EKS ASING TERHADAP HASIL TANGKAPAN NELAYAN LEBIH KECIL 30 GT DI BITUNG SULAWESI UTARA
}

\author{
Impact Evaluation of Licensing Moratorium on Exforeign Ships Against \\ The Catch of Smaller Fishermen 30 GT In Bitung, North Sulawesi
}

\author{
Sulaeman Rusdi ${ }^{1)}$, Asbar ${ }^{2)}$ dan Danial ${ }^{2)}$ \\ 1) Mahasiswa PS Manajemen Pesisir dan Teknologi Kelautan, PPS UMI \\ 2) Program Studi Ilmu Kelautan FPIKUMI \\ Korespondensi: sulaemanrusdi@gmail.com
}

Diterima: tanggal 5 November 2018; Disetujui 30 November 2018

\begin{abstract}
One of the policies issued by the Ministry of Maritime Affairs and Fisheries in anticipation of the occurrence of IUU Fishing is the moratorium policy of ex-foreign vessels as stipulated in Ministerial Regulation No. 56/2014. The presence of this policy is also one way to overcome the exploitation of Indonesia's marine resources. This study aims to determine the differences in fish catches smaller than 30 GT, knowing the impact of the moratorium policy on permits for ex-foreign vessels to catch smaller fishermen 30 GT and knowing the direction of fisheries resource management in the Republic of Indonesia fisheries management area RI) 716. The comparative analysis of the two samples correlated with the results turns out that there are differences in the level of catches of the smaller fishermen 30 GT before and after the moratorium (2013 and 2016). The impact of the moratorium on the licensing of ex-foreign vessels on fishermen has led to an increase in unemployment of local $A B K$ and ex-foreign ship crews, while fishing vessels smaller than 30 GT have increased their catch. The fisheries resource management strategy in the fisheries management area (WPPRI) 716 is to build cooperation of all relevant agencies that allow access to capital and provide guidance in terms of increasing knowledge and skills to increase fishermen's catches by $30 \mathrm{GT}$ to the direction of fisheries management.
\end{abstract}

Keywords: Moratorium, Smaller Ship 30GT, Comparative, Descriptive, SWOT

\begin{abstract}
ABSTRAK
Salah satu kebijakan yang dikeluarkan oleh Kementerian Kelautan dan Perikanan dalam mengantisipasi terjadinya IUU Fishing adalah kebijakan moratorium eks kapal asing yang tertuang dalam Peraturan Menteri No. 56/2014. Kehadiran kebijakan ini juga menjadi salah satu cara untuk mengatasi eksploitasi sumberdaya laut Indonesia. Penelitian ini bertujuan untuk menentukan perbedaan hasil tangkapan ikan nelayan lebih kecil 30 GT, mengetahui dampak kebijakan penghentian sementara (moratorium) perizinan kapal eks asing terhadap hasil tangkapan nelayan lebih kecil 30 GT dan mengetahui arah pengelolaan sumberdaya perikanan di wilayah pengelolaan perikanan Republik Indonesia (WPP-RI) 716. Analisis komparatif dua sampel berkorelasi hasilnya ternyata ada perbedaan tingkat hasil tangkapan nelayan lebih kecil 30 GT sebelum dan sesudah moratorium (Tahun 2013 dan 2016). Dampak kebijakan moratorium perizinan kapal eks asing pada nelayan menyebabkan adanya peningkatan pengangguran ABK lokal maupun ABK kapal eks asing, sedangkan kapal nelayan yang berukuran lebih kecil dari 30 GT meningkat hasil tangkapannya. Strategi pengelolaan sumberdaya perikanan di wilayah pengelolaan perikanan (WPPRI) 716 adalah membangun kerjasama semua instansi terkait yang memungkinkan memperoleh akses modal dan memberikan bimbingan dalam hal peningkatan pengetahuan dan keterampilan untuk meningkatkan hasil tangkapan nelayan lebih kecil 30 GT terhadap arah pengelolaan perikanan.
\end{abstract}

Kata kunci: Moratorium, Kapal lebih Kecil 30GT, Komparatif, Deskriptif, SWOT 


\section{PENDAHULUAN}

Kebijakan moratorium kapal-kapal yang dibuat di luar negeri didasari tujuan untuk mewujudkan pengelolaan perikanan yang bertanggung jawab, dan penanggulangan Illegal, Unreported and Unregulated (IUU) Fishing di Wilayah Pengelolaan Perikanan Negara Republik Indonesia (WPPNRI) perlu dilakukan penghentian sementara (Moratorium) perizinan usaha perikanan tangkap. Berdasarkan pertimbangan tersebut Menteri Kelautan dan Perikanan tentang penghentian sementara (moratorium) perizinan usaha perikanan tangkap di wilayah pengelolaan perikanan negara republik Indonesia. Aktivitas IUU Fishing dinilai telah merugikan perekonomian Indonesia sebesar USD 3,125 million atau Rp. 30 trilium pertahun (Badan Pemeriksa Keuangan, 2013).

Salah satu kebijakan yang dikeluarkan oleh Kementerian Kelautan dan Perikanan dalam mengantisipasi terjadinya IUU Fishing adalah kebijakan moratorium eks kapal asing yang tertuang dalam Peraturan Menteri No. 56/2014 yang isinya adalah kapal yang pembuatannya dilakukan di luar negeri tidak akan dberikan izin baru Surat Ijin Usaha Perikanan (SIUP), Surat Ijin Penangkapan Ikan (SIPI), Surat Ijin Kelayakan Penangkapan Ikan (SIKPI) dan perpanjangan SIPI dan SIKPI. Kebijakan ini diambil pemerintah karena kerugian besar dari sektor kelautan dan perikanan yang disebabkan beroperasinya kapalkapal eks asing tersebut dan sebagai bentuk antisipasi terjadinya IUU Fishing. Berdasarkan kajian awal dari Institut
Pertanian Bogor (IPB) sebelum diterapkan kebijakan moratorium tersebut diperoleh informasi bahwa terdapat 1.240 kapal buatan asing dari total 5.329 kapal yang berukuran di atas 30 GT di Indonesia (Kurniawan, 2014).

Kehadiran kebijakan ini juga menjadi salah satu cara untuk mengatasi eksploitasi atas laut Indonesia (overfishing) dan menjadi sarana dalam memperbaiki ekosistem bahari serta mereformulasi tata kelola industri yang merupakan hilir dari ekosistem pengelolaan sektor perikanan Indonesia. Harapannya ini bisa menjadi momentum membangun dan memanfaatkan sektor perikanan Indonesia demi mewujudkan masyarakat nelayan yang lebih sejahtera.

Berdasarkan uraian diatas, maka perlu dilakukan penelitian tentang evaluasi dampak moratorium perizinan kapal eks asing terhadap hasil tangkapan nelayan lebih kecil 30 GT di Bitung Sulawesi Utara dengan terlebih dahulu menentukan hasil produksi perikanan laut yang dirataratakan dalam Tahunan menggunakan Analisis Komparatif Dua Sampel Berkorelasi.

Penelitian ini bertujuan untuk mengetahui perbedaan tingkat hasil tangkapan nelayan lebih kecil 30 GT di Bitung Sulawesi Utara sebelum dan sesudah moratorium merumuskan strategi pengelolaannya.

\section{METODE PENELITIAN}

Penelitian ini dilaksanakan pada bulan Agustus s/d September 2018 di Bitung Sulawesi Utara dengan lokasi Pelabuhan Perikanan Samudera Bitung (PPS Bitung), sebagaimana pada gambar berikut: 


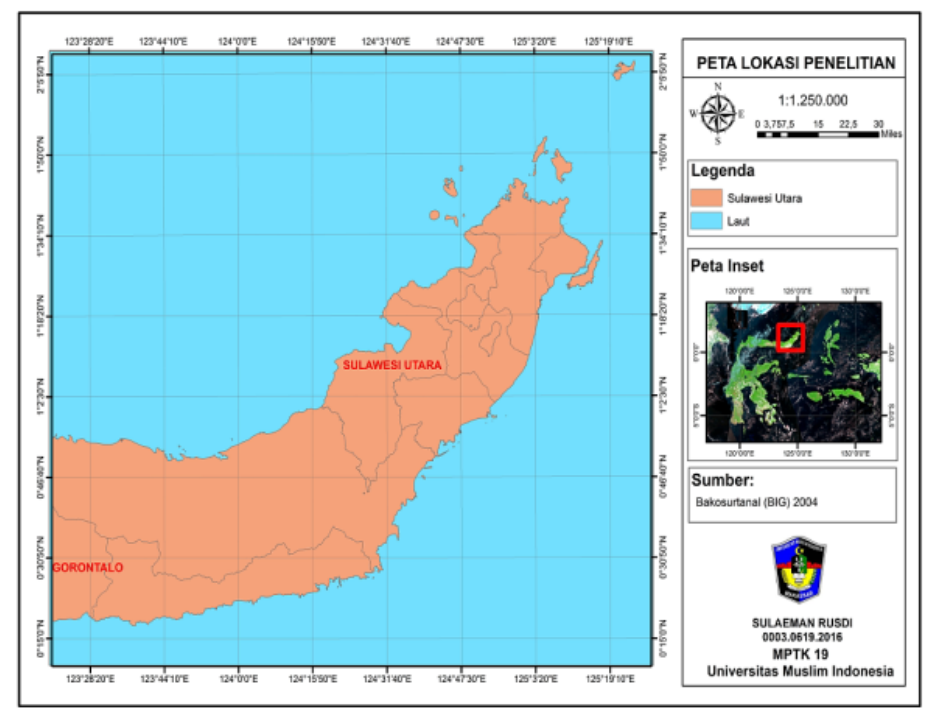

Gambar 1. Peta Lokasi Penelitian

Alat dan bahan yang digunakan dalam penelitian ini yaitu alat tulis, kamera HP, komputer dan flasdisk untuk mengolah dan menyimpan data hasil tangkapan nelayan lebih kecil 30 GT tahun 20132016.

Penelitian ini menggunakan metode survey lapangan dan wawancara serta pemberian quesionar pada nelayan lebih kecil 30 GT. Pengumpulan data primer dilakukan pada saat melakukan survey di PPS Bitung data sebelum dan sesudah moratorium diberlakukan ukuran kapal nelayan lebih kecil 30 GT. Data sekunder diperoleh dari sumber-sumber bacaan, buku-buku referensi, jurnal, dan internet yang berhubungan dengan kegiatan penelitian. Penentuan responden pada masyarakat lokal dilakukan dengan teknik purpossive sampling artinya penentuan lokasi dan responden dengan beberapa pertimbangan tertentu oleh peneliti berdasarkan ciri atau sifat-sifat populasi yang sudah diketahui sebelumnya (Notoatmodjo, 2002). Pertimbangan tertentu yang dimaksud adalah orang yang dijadikan responden mereka secara langsung terlibat sebagai nelayan lebih kecil 30 GT dilokasi penelitian pelabuhan perikanan samudera Bitung.

Data dianalisis menggunakan analisis komparatif dua sampel berkolerasi. Setelah diketahui perbandingan rata-rata hasil tangkapan nelayan lebih kecil 30 GT tahun 2013 dan 2016 selanjutnya di Uji untuk mengetahui ada tidaknya perbedaan nilai rata-rata antara dua kelompok data yang berpasangan di gunakan uji-t dua sampel (sampel paired test) (Syofian Siregar, 2017).

Metode deskriptif dapat diartikan sebagai prosedur pemecahan masalah yang diselidiki dengan menggambarkan/melukiskan keadaan /obyek penelitian pada saat sekarang berdasarkan fakta-fakta yang tampak, atau sebagaimana adanya (Amiriddin, 2016).

Analisis SWOT (Strength, Weaknes, Opportuniy and Theart) digunakan untuk merumuskan strategi arah pengelolaan 
sumberdaya perikanan. Adapun langkahlangkah yang dilakukan dalam analisis SWOT (Strength, Weaknes, Opportuniy and Theart) yaitu: (1) Identifikasi Kekuatan, Kelemahan, Peluang dan Ancaman; (2) Analisis SWOT; (3) Arahan Strategi Pengelolaan Hasil Analisa SWOT.

\section{HASIL DAN PEMBAHASAN}

Kota Bitung terletak pada posisi geografis $1^{\circ} 23^{\prime} 23^{\prime \prime}-1^{\circ} 35^{\prime} 39^{\prime \prime} \mathrm{LU}$ dan $125^{\circ} 1^{\prime} 43^{\prime \prime}-125^{\circ} 18^{\prime} 13^{\prime \prime}$ BT. Kota Bitung memiliki batas-batas sebagai berikut : Utara - Berbatasan dengan Kecamatan Likupang (Kabupaten Minahasa Utara) dan Laut Maluku; Selatan - Berbatasan dengan Laut Maluku; Barat - Berbatasan Kecamatan Kauditan (Kabupaten Minahasa Utara); Timur - Berbatasan dengan Laut Maluku.

Berdasarkan letak geografisnya Kota Bitung terletak di daratan Pulau Sulawesi dan sebagian adalah daerah kepulauan yaitu Pulau Lembeh. Kota Bitung terdiri dari 8 (delapan) Kecamatan, 6 (enam) Kecamatan terletak di Pulau Sulawesi yaitu Kecamatan Madidir, Matuari, Girian, Aertembaga, Maesa dan Ranowulu dan 2 Kecamatan terletak di Pulau Lembeh yaitu Lembeh Selatan dan Lembeh Utara. Wilayah Bitung mempunyai daratan seluas $304 \mathrm{~km}^{2}$ dan lautan seluas $714 \mathrm{~km}^{2}$. Total Panjang garis pantai $143,2 \mathrm{~km}$, terdiri dari 46,3 Km di daratan utama dan 98,9 km keliling Pulau Lembeh serta pulau-pulau kecil lainnya.

\section{- Perbedaan Hasil Tangkapan Nelayan Lebih Kecil 30 GT sebelum dan Sesudah Moratorium}

Untuk mengetahui nilai rata-rata produksi hasil tangkapan nelayan lebih kecil 30 GT sebelum dan sesudah moratorium tahun 2013 dan 2016 di Bitung berikut ini:

Tabel 1. Perhitungan Hasil Tangkapan Nelayan Lebih Kecil 30 GT Tahun 2013 dan 2016 untuk di Analisis Komparatif Dua Sampel Berkolerasi

\begin{tabular}{|c|c|c|c|c|c|}
\hline \multirow{2}{*}{ No } & \multirow{2}{*}{ Tahun } & \multicolumn{3}{|c|}{ Ukuran GT Kapal } & \multirow[b]{2}{*}{$20-30$} \\
\hline & & $<5$ & $5-10$ & $10-20$ & \\
\hline \multicolumn{6}{|c|}{ Sebelum Moratorium Tahun 2013} \\
\hline 1 & 2013 & 1.165 .515 & 2.704 .243 & 931.610 & 7.272 .893 \\
\hline \multicolumn{6}{|c|}{ Sesudah Moratorium Tahun 2016} \\
\hline 2 & 2016 & 1.710 .907 & 3.099 .713 & 1.405 .333 & 11.684 .654 \\
\hline
\end{tabular}

Berdasarkan Tabel 1 menunjukan bahwa terdapat perbedaan hasil tangkapan nelayan lebih kecil 30 GT sebelum dan sesudah moratorium. Berikut perbedaan hasil tangkapan nelayan lebih kecil 30 GT sebelum dan sesudah moratorium berikut ini: 


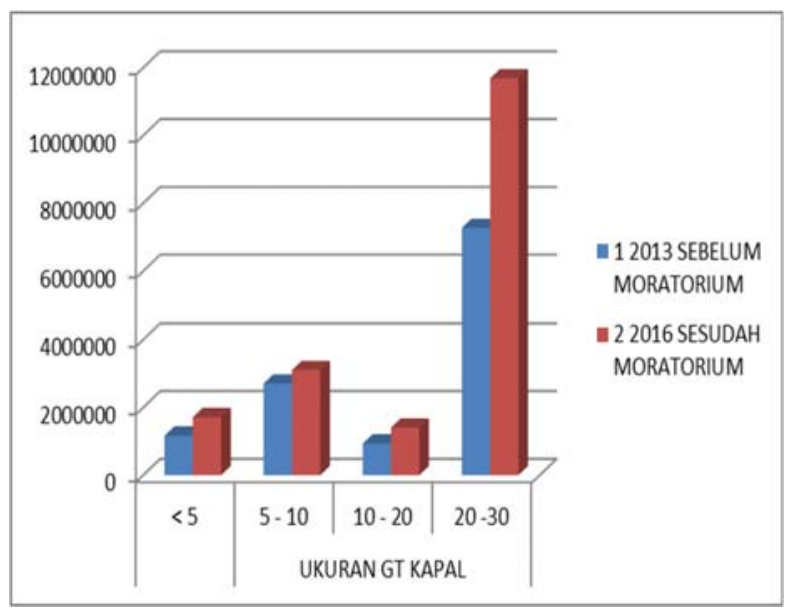

Gambar 1. Grafik sebelum dan sesudah moratorium 2013 dan 2016

Perbedaan Hasil Tangkapan Sebelum dan Sesudah Moratorium dilakukan Analisis Komparatif Dua Sampel Berkorelasi

Dengan taraf kepercayaan 95\% (taraf signifikan $\alpha=0,05)$. Ujilah apakah ada perbedaan hasil tangkapan kapal nelayan lebih kecil 30 GT sebelum dan sesudah moratorium. Adapun hasil didapat menentukan nilai tabel dan membandingkan $t_{\text {tabel }}$ dan thitung ternyata $-0,609>-3,182$, maka Ho ditolak. Dapat disimpulkan ada perbedaan tingkat hasil tangkapan kapal nelayan lebih kecil 30 GT sebelum dan sesudah moratorium.

\section{Dampak Kebijakan sebelum dan} Sesudah Moratorium (Analisis

\section{Deskriptif)}

Kebijakan moratorium telah memberikan dampak positif dan dampak negatif perikanan tangkap di Kota Bitung Sulawesi Utara berikut ini:

Tabel 2. Kondisi Perikanan Tangkap Sebelum dan Sesudah Moratorium Kapal Nelayan Lebih Kecil 30 GT, Kapal Eks Asing dan UPI di Kota Bitung Tahun 2013 2016

\begin{tabular}{|c|c|c|}
\hline \multirow[b]{2}{*}{ Uraian } & \multicolumn{2}{|r|}{ Bitung } \\
\hline & $\begin{array}{c}\text { Sebelum Permen } \\
56 / 2014 \\
\end{array}$ & $\begin{array}{c}\text { Sesudah } \\
\text { Permen 56/2014 }\end{array}$ \\
\hline \multicolumn{3}{|c|}{ Dampak Positif } \\
\hline Produksi & $\begin{array}{l}\text { Produksi kapal 100-500 } \\
\text { kg/trip }\end{array}$ & Produksi kapal meningkat $200 \%$ \\
\hline Jumlah trip & $\begin{array}{l}\text { - Jumlah trip kapal }<10 \\
\text { GT sebanyak 2-3 } \\
\text { hari/trip } \\
\text { - Jumlah trip kapal } 10- \\
\text { 30 GT sebanyak }> \\
\text { minggu }\end{array}$ & $\begin{array}{l}\text { - Jumlah trip kapal }<10 \mathrm{GT} \text { meningkat } \\
\text { menjadi } 1 \text { hari/trip } \\
\text { - Jumlah trip kapal } 10-30 \mathrm{GT} \\
\text { meningkat menjadi }<\text { Minggu }\end{array}$ \\
\hline
\end{tabular}




\begin{tabular}{|c|c|c|}
\hline \multirow[b]{2}{*}{ Uraian } & \multicolumn{2}{|r|}{ Bitung } \\
\hline & $\begin{array}{c}\text { Sebelum Permen } \\
56 / 2014\end{array}$ & $\begin{array}{c}\text { Sesudah } \\
\text { Permen } 56 / 2014\end{array}$ \\
\hline Pendapatan & 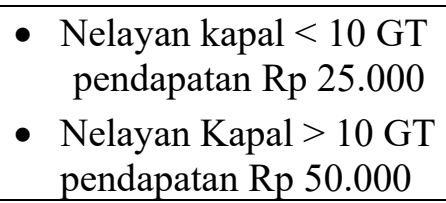 & $\begin{array}{l}\text { - } \text { Pendapatan nelayan kapal }<10 \mathrm{GT} \\
\text { meningkat Rp } 75.000 \\
\text { - } \begin{array}{l}\text { Pendapatan nelayan kapal }>10 \mathrm{GT} \\
\text { meningkat Rp } 100.000\end{array}\end{array}$ \\
\hline $\begin{array}{l}\text { Jarak } \\
\text { Fishing } \\
\text { Ground }\end{array}$ & $\begin{array}{l}\text { - Wilayah penangkapan } \\
\text { kapal di lokasi } 4 \text { mil }\end{array}$ & $\begin{array}{l}\text { - Wilayah tangkapan berkurang } 2 \text { mil } \\
\text { karena sudah banyak ikan }\end{array}$ \\
\hline Harga Ikan & $\begin{array}{l}\text { - Harga ikan hasil } \\
\text { tangkapan nelayan Rp } \\
5.000 / \mathrm{kg}\end{array}$ & $\begin{array}{l}\text { - } \text { Terjadi peningkatan harga ikan } \\
\text { menjadi Rp } 10.000 / \mathrm{kg}\end{array}$ \\
\hline $\begin{array}{l}\text { Penggunaa } \\
\text { BBM }\end{array}$ & $\begin{array}{l}\text { - Akses BBM untuk } \\
\text { nelayan sulit }\end{array}$ & - Akses memperoleh BBM lebih mudah \\
\hline $\begin{array}{l}\text { Jumlah } \\
\text { kapal yang } \\
\text { melaut }\end{array}$ & $\begin{array}{l}\text { - Kapal yang beroperasi } \\
\text { terbatas }\end{array}$ & - Jumlah operasi ka \\
\hline & Dampal & k Negatif \\
\hline Produksi & $\begin{array}{l}\text { - Waktu produksi } 7 \text { hari } \\
\text { kerja/minggu } \\
\text { - Pasokan ikan stabil }\end{array}$ & $\begin{array}{l}\text { - Waktu produksi } 2-3 \text { hari kerja/minggu } \\
\text { - Berkurang }>50 \% \text { karena kekurangan } \\
\text { bahan baku }\end{array}$ \\
\hline $\begin{array}{l}\text { Jumlah UPI } \\
\text { yang masih } \\
\text { beroperasi }\end{array}$ & $\begin{array}{l}\text { - Jumlah UPI di dalam } \\
\text { pelabuhan } 8 \text { unit }\end{array}$ & $\begin{array}{l}\text { - Jumlah UPI di dalam pelabuhan yang } \\
\text { beroperasi } 6 \text { unit }\end{array}$ \\
\hline $\begin{array}{l}\text { Tenaga } \\
\text { Kerja }\end{array}$ & $\begin{array}{l}\text { - } 700.000 \text { per minggu } \\
\text { - Jumlah jam kerja } 60 \\
70 \text { jam per minggu }\end{array}$ & $\begin{array}{l}\text { - Terjadi pengurangan tenaga kerja } \\
\text { - Dilakukan system rolling pegawai } \\
\text { - Jumlah jam kerja } 12-24 \text { jam per } \\
\text { minggu }\end{array}$ \\
\hline $\begin{array}{l}\text { Supply ikan } \\
\text { ke pasar }\end{array}$ & - Normal & Supply ikan kalengan berkurang $70 \%$ \\
\hline $\begin{array}{l}\text { Pasokan } \\
\text { Bahan Baku }\end{array}$ & $\begin{array}{l}\text { - Sumber pasokan dar } \\
\text { dalam Bitung }\end{array}$ & $\begin{array}{l}\text { - Berkurang hanya mengandalkan } \\
\text { pasokan dari kapal-kapal kecil } \\
\text { - UPI Cakalang fufu (asap) pasokan } \\
\text { bahan baku berkurang sebanyak 50\% }\end{array}$ \\
\hline ABK Kapal & $\begin{array}{ll}\text { Tidak } & \text { ada } \\
\text { pengangguran } & \text { ABK } \\
\text { Eks Asing dan } & \text { ABK } \\
\text { Lokal } & \\
\end{array}$ & $\begin{array}{l}\text { - Meningkat Pengangguran ABK Asing } \\
\text { dan ABK Lokal }\end{array}$ \\
\hline
\end{tabular}

Sumber: Hasil Penelitian, 2018 


\section{Strategi Arah Pengelolaan Sumberdaya Perikanan (Analisis SWOT)}

Faktor kekuatan (strength) antara lain: potensi sumberdaya perikanan, potensi sumberdaya manusia, hasil tangkapan nelayan lebih kecil 30 GT yang terus meningkat. Unsur kelemahan (weakness) antara lain: tingkat pendidikan dan ketrampilan yang relatif masih rendah, modal masyarakat nelayan masih kurang, bahan baku UPI berkurang. Unsur peluang (opportunity) antara lain: dukungan pemerintah, frekuensi kunjungan kapal dan pendaratan hasil tangkapan nelayan lebih kecil 30 GT terus meningkat. Unsur ancaman (threat) antara lain: dihentikannya moratorium, Nelayan dari luar, jumlah kapal nelayan lebih besar 30 GT bertambah.

Berdasarkan faktor internal dan eksternal tersebut, maka disusun rencana strategi arah pengelolaan arah sumberdaya perikanan di Bitung Sulawesi Utara metode SWOT dan ditetapkan 8 (delapan) strategi terbaik antara lain: (1) Pengelolaan sumberdaya perikanan secara optimal dengan melibatkan semua instansi terkait; (2) Meningkatkan kualitas sumberdaya manusia agar mampu memanfaatkan sumberdaya perikanan dan laut secara optimal; (3) Pengembangan arah pengelolaan sumberdaya perikanan untuk meningkatkan hasil tangkapan nelayan lebih kecil 30 GT; (4) Memberikan bimbingan dalam hal peningkatan pengetahuan dan keterampilan untuk meningkatkan hasil tangkapan nelayan lebih kecil 30 GT; (5) Pengadaan koperasi simpan pinjam untuk mengatasi kesulitan modal; (6) Mendorong bahan baku UPI untuk meningkatkan produksi; (7) Adanya persiapan nelayan lebih kecil 30 GT untuk mengantisipasi hasil tangkapan setelah moratorium di hentikan; (8) Membangun kerjasama yang memungkinkan memperoleh akses modal untuk meningkatkan hasil tangkapan terhadap arah pengelolaan perikanan.

\section{KESIMPULAN}

Berdasarkan hasil penelitian evaluasi dampak moratorium perizinan kapal eks asing terhadap hasil tangkapan nelayan lebih kecil 30 GT di Bitung Sulawesi Utara, maka dapat disimpulkan sebagai berikut:

1. Hasil analisis komparatif dua sampel berkorelasi hasilnya ternyata ada perbedaan tingkat hasil tangkapan nelayan lebih kecil 30 GT sebelum dan sesudah moratorium;

2. Dampak kebijakan moratorium perizinan kapal eks asing pada nelayan menyebabkan meningkat pengangguran ABK lokal maupun ABK kapal eks asing, sedangkan nelayan yang berukuran lebih kecil dari 30 GT meningkat hasil tangkapannya;

3. Strategi pengelolaan sumberdaya perikanan di wilayah pengelolaan perikanan (WPPRI) 716 adalah membangun kerjasama semua instansi terkait yang memungkinkan memperoleh akses modal dan memberikan bimbingan dalam hal 
4. peningkatan pengetahuan dan keterampilan untuk meningkatkan hasil tangkapan nelayan lebih kecil 30 GT terhadap arah pengelolaan perikanan.

\section{SARAN}

1. Dengan adanya kebijakan moratorium Permen No.56/2014 tentang perizinan kapal esk asing yaitu ABK kapal eks asing perlu dilaksanakan sosialisasi tentang kebijakan yang akan ditetapkan, agar pihak yang akan merasakan dampak dari kebijakan tersebut dapat melakukan persiapan;

2. Melakukan pengawasan pada saat pelakanaan suatu kebijakan, agar pemerintah dapat mengetahui apakah kebijakan yang ditetapkan telah dilaksanakan sesuai dengan tujuannya.

3. Perlu dilakukan penelitian lanjutan mengenai kontribusi arah pengelolaan sumberdaya perikanan di Bitung Sulawesi Utara untuk meningkatkan hasil tangkapan nelayan lebih kecil 30 GT setelah moratorium dihentikan.

\section{UCAPAN TERIMA KASIH}

Tulisan ini merupakan bagian dari penelitian tesis pada program studi Manajemen Pesisir dan Teknologi Kelautan dan penulis mengucapkan terima kasih kepada Pemerintah Kota Bitung yang telah memberikan izin dan dukungan data selama penelitian.

\section{DAFTAR PUSTAKA}

Badan Pemeriksa Keuangan (BPK). 2013. Audit IUU Fishing. Lampiran Siaran Pers Badan Pemeriksa Keuangan. http://www.bpk.id/ assets/ files/ storage/ 2013/ 12/file_storage_1386744323.pdf.diu nduh Maret 2015.

Badan Pusat Statistik Kota Bitung (BPS Bitung). Kota Bitung Dalam Angka 2018.

Kurniawan, A. 2014. Susi Usul Subsidi untuk Kapal Besar Dihapuskan. http://www.indopos.co.id/2014/11/s usi-usul-subsidi-untuk-kapal-besardihapuskan.html.

Peratutan Menteri Kelautan dan Perikanan Republik Indonesia Nomor 56/Permen-KP/2014 tentang Penghentian Sementara (Moratorium) Perizinan Usaha Perikanan Tangkap di Wilayah Pengelolaan Perikanan Negara Republik Indonesia.

Pengertian Moratorium Menurut Para Ahli.http://www. Definisi menurut para ahli. com/pengertian moratorium.

Siregar S. 2017 "Statistik Parametrik Untuk Penelitian Kuantitatif Dilengkapi dengan Perhitungan Manual dan Aplikasi SPPS Versi 17" Penerbit PT Bumi Aksara, Jakarta. 